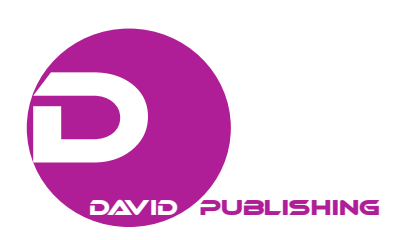

\title{
Information Technology (IT) Architecture Based on Cloud Computing for Muhammadiyah Higher Education Institutions (HEIs)
}

\author{
Endy Sjaiful Alim \\ Huazhong University of Science and Technology (HUST), Wuhan, China \\ University of Muhammadiyah Prof. Dr. HAMKA (UHAMKA), Jakarta, Indonesia
}

\begin{abstract}
Muhammadiyah Universities are the largest private university network in Indonesia. Generally, they have similar business process and information system (IS) requirements. However, in reality, each university builds its own architecture and IS. Problems often arise regarding the redundancy of the IS, the lack of a standardized data structure, the absence of data consolidation between ISs and the inconsistency of IS development. These problems are the basic premise for designing an information technology (IT) architecture model using the concept of cloud computing. Based on the results of analyzing the conditions of the university using the chosen framework, an IT architecture model based on cloud computing that corresponds to the condition and requirements of Muhammadiyah Universities in Indonesia was created. This architecture consists of business, data, application, and technology architectures. This research is expected to contribute to the Muhammadiyah Universities, especially as a reference in designing IT architecture.
\end{abstract}

Keywords: cloud computing, information technology (IT) architecture, higher education information system (IS)

\section{Introduction}

Information technology (IT) architecture in an institution is a blueprint that explains how the elements of IT and management work together as a unit. The appropriate implementation of the IT architecture will greatly assist the achievement of the institution's objectives, including educational institutions. The Muhammadiyah Universities, as private educational institutions in Indonesia, also need IT to conduct their business processes. Planning of the IT architecture is an important issue, so that the strategy of the technology is consistent with the business strategy of the university. However, currently there is no widely available model for the framework or IT architecture that is appropriate for implementation in Muhammadiyah higher education institutions (HEIs) in Indonesia. The available IT architecture models are mostly only narrow in scope in some of the education institutions.

Hewitt (2008) stated that the technology of cloud computing is a technology where most of the process and computation is located in the internet, allowing users to access the required service from anywhere. A

Endy Sjaiful Alim, M.Sc., Ph.D. student, Computer Science Program, researcher at Lab Service Computing Technology and System, Huazhong University of Science and Technology (HUST); lecturer, University of Muhammadiyah Prof. Dr. HAMKA (UHAMKA). 
cloud computing platform is a set of large-scale server data, providing a computation and storage service to customers. Cloud storage is a service that is relatively basic and can be applied widely to users on an equal basis, by providing large storage space. Cloud computing gives added value to the design of IT architecture for institutions, including educational institutions. Research conducted by Xu, M. Song, Zhang, and J. Song (2009) showed that one part of the system architecture for cloud computing today was a structured model center. Cloud computing can reduce the management costs (Xu et al., 2015). For cloud computing management (Luo et al., 2012), especially for high-level cloud computing, the evolution of the cloud computing strategy should be based on growing the cloud from the external toward the internal cloud. The concept of an intelligent architecture for implementation in an educational institution (college) using cloud computing has been tested at the Department of Computer Science and Engineering, University of Kalyani (Guin et al., 2011).

Muhammadiyah is the largest non-governmental organization in Indonesia. Muhammadiyah emphasizes its main activities as providing qualified education. According to data from the Central Board of Muhammadiyah in 2015, there were 177 Muhammadiyah HEIs throughout Indonesia, making Muhammadiyah the biggest private higher education network in Indonesia. Although each Muhammadiyah University has the autonomy to organize its own business processes, generally they have a similar basis in the curriculum. Muhammadiyah Universities must respect and obey the government as policy maker, and it has standardized the education provision through Law No. 20 in 2003 of the National Education System. In the law, as stated in Article 20 Paragraph 2, the universities are obliged to provide education, research, and community service. Generally, Muhammadiyah Universities have similar business processes. The similarity of the characteristics of these business processes will be used as the basis for designing the architecture model for Muhammadiyah higher education in Indonesia.

\section{Literature Review}

\section{IT Architecture}

According to Seigerroth (2011), “Architecture is the strategic information that defines a company's mission, as well as the required IT and what it will take to achieve the mission. The architecture is a firm goal to be achieved or that is to be constructed." To achieve the goal, we need a structured plan and measures, so it can be achieved gradually. Basic architecture of an enterprise is an architecture condition that already exist, for example, an enterprise network architecture. Enterprise architecture consists of basic architecture, architecture, and planning purposes that are structured to achieve the goal.

IT architecture is the basic organization of the intensive software systems. A system is software-intensive, because the most prominent part of the architecture is the application of IT. This part allows the users to perform their business work. The framework or IT architecture design framework, is now widely available. Nevertheless, it has basically the same goal, which makes it easy to design the architecture for IT in a company. According to Zachman (2008), the examples of an IT architecture framework that were most widely used were the Enterprise Architecture (EA) framework and The Open Group Architecture Framework (TOGAF).

TOGAF is an industry standard for the method development, architecture, and resource base and can be used freely by any organization wishing to develop an enterprise architecture for internal company use. TOGAF has been developed continuously since the Mid-1990s by representatives of several user organizations and leading vendors of IT. They collaborate further on The Open Group Architecture Forum to develop TOGAF. 
TOGAF provides a variety of methods and tools to assist companies in preparing, developing, using, and maintaining the architecture for their company. TOGAF is continually being refined based on best practice from various companies and organizations. The TOGAF architecture supports four types, namely: business architecture, data architecture, application architecture, and technology architecture.

Business architecture defines the business strategy, key business processes, and the supporting organization and management. Data architecture defines the structure of the data and resources owned by the company, both physically and logically. One example of the architecture of the data in educational institutions concerns the data storage structure for faculty and students.

One form of enterprise application in the architecture can be seen in the IT planning document (IT Plan). TOGAF also supports a technology architecture that illustrates the need for software, hardware, and networks to support business processes and other architectures.

TOGAF, as an IT architecture framework, has phases that make up the development cycle of the IT architecture. The cycle is referred to as the architecture development method (ADM). ADM is composed of a single phase of preparation, eight parts of the main phase and a process to manage and organize the whole ADM phase.

\section{Cloud Computing}

Cloud computing has become a promising commercial form of computing. A cloud computing platform provides easy access to high performance computing, storage, and infrastructure that is accessible via Web services provided specifically for companies and institutions (Wu \& Lee, 2012). Cloud computing can reduce the level of complexity of the IT infrastructure management of its users. At the same time, the cloud computing platform provides great scalability, 99.999\% reliability, high-performance, and can be configured to specific user needs.

Cloud computing has great advantages for on-demand computing, scalability, proactive resource management, better application throughput, and security. Because of its openness and the ability to adapt to technological developments, it can be the right choice for non-profit organizations to equip them with the resources needed at minimum cost (Malik, Huet, \& Carome, 2012).

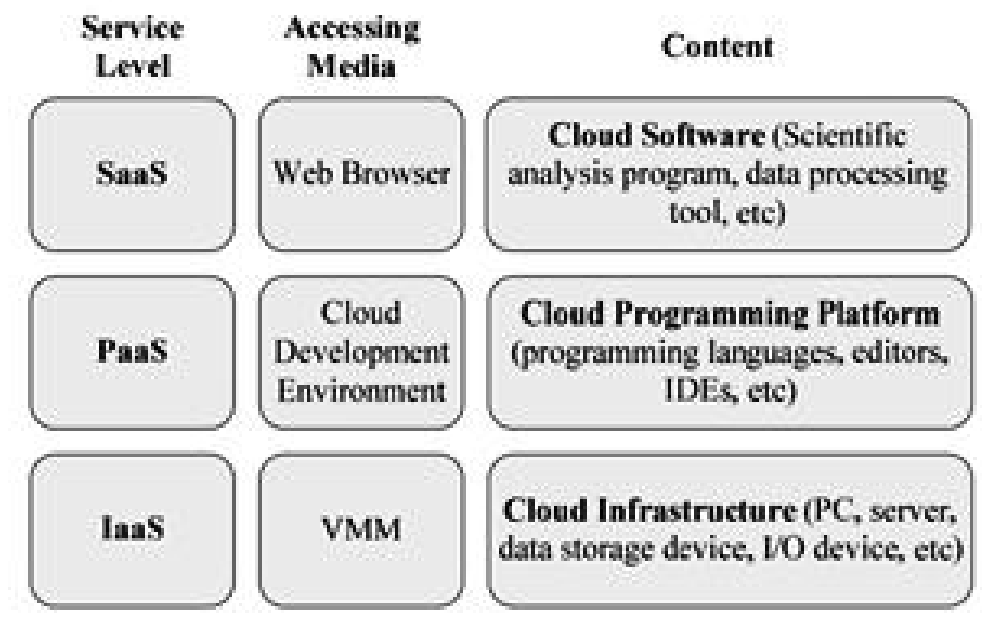

Figure 1. Service model of cloud computing.

Judging from the development models, cloud computing consists of four models: the private cloud, 
community cloud, public cloud, and hybrid cloud. As concerns the concept of cloud computing services, there are three levels of service (see Figure 1), namely: Infrastructure as a Service (IaaS), Platform as a Service (PaaS), and Software as a Service (SaaS). Cloud computing can provide services from different layers, and each layer is on different level (Luo et al., 2012).

\section{IT Architecture for Higher Education in Indonesia}

According to earlier research (Solichin \& Hasibuan, 2012), the data architecture developed by universities has been quite good, but it still generates problems if it needs to be integrated with data derived from other universities. In other words, the data structure that is owned by the college is still not ready to be integrated. In the current data architecture, some important data from lecturers, students, and other academic data must be reported to the Directorate General of Higher Education. Reporting of data is still done manually, so it appears problematic. Problems often arise when other media used are not readable by applications in higher education, so the universities need to fix these first. Additionally, process data changes cannot be done quickly.

Table 1

Mapping Application for Muhammadiyah Universities With Mcfarlan Strategic Grid

\begin{tabular}{|l|l|}
\hline Strategic & High potenitial \\
\hline Project management IS & \\
Executive IS & \\
Knowledge management system & \\
\hline Academic report IS & Student IS \\
Admission IS & Staffing IS \\
Academic IS & Inventory IS \\
Learning IS & Financial IS \\
Curriculum IS & Website \\
Library IS & E-mail \\
Laboratory IS & Blog \\
Research \& development IS & \\
\hline Kemuhammadiyahan IS & Suport \\
\hline Key operation & \\
\hline
\end{tabular}

Based on the results of the mapping of ISs in colleges (see Table 1), there are various applications in suport category, namely: student IS, staffing IS, inventori IS, financial IS, Website, E-mail, and Blog. These applications are practically required in colleges, but do not significantly affect the main business processes of those colleges.

In the key operational category, there are nine applications of IS, namely: Admissions ISs, Academic ISs, Learning Management System (LMS), Learning IS (e-Learning), Library IS (e-Library), Laboratory ISs (e-Laboratory), Curriculum ISs (e-Curriculum), Research \& Development ISs, Alumni ISs, and the Academic Report ISs. These nine applications over a (main) core application should be available at every university in Indonesia. If one or more of the applications is not available, then the process will interrupt college business or raise obstacles. Therefore, the application will involve these nine services in the cloud for the entire college. For those lodging in a Muhammadiyah college, there is a special feature implementation for the development of religion in social life (Keislaman and Kemuhammadiyahan). To support these activities, the required separate IS applications are also included in the key operations.

Meanwhile, there are three ISs included in the strategic category, namely: the executive IS, IS project management, and knowledge management system. The implementation of the IS will affect the 
competitiveness (competitive advantage) for universities, yet in the groups that have high application potential, there is no IS. Currently, colleges in general do not have an IS that has high potential. In relation to education, especially higher education, a high potential application is an application that can be the basis to enable the government or universities to adopt a policy.

\section{Research Method}

Based on the above background, this research was designed in accordance with an architectural model of IT based on the conditions and needs of the Muhammadiyah Universities in Indonesia. In this study, we will discuss:

1. How to model the IT architecture based on cloud computing technology that is appropriate for Muhammadiyah HEIs in Indonesia;

2. What are the components of IT architecture-based cloud computing for the Muhammadiyah Universities in Indonesia;

3. What services can be provided by cloud computing providers in the IT architecture model for Muhammadiyah Universities.

The methodology used to compile the IT architecture is the TOGAF ADM (2007).

\section{Results}

\section{Application Architecture}

The cloud-based application architecture in Muhammadiyah Universities illustrates the position of applications as a service that will be placed in the cloud, as well as how good the relationships are between every application in the cloud as well as with other applications outside the cloud.

Several universities in Indonesia have a private network "Inherent." However, due to not all Muhammadiyah Universities are connected to "Inherent," the network among Muhammadiyah Universities is connected via the Internet (see Figure 2).

If we analyze it in more detail, there is a relationship between each of the applications in the cloud. For example, the new admissions system will deal with the academic IS, especially in terms of data on students who are newly admitted. Furthermore, the academic IS is also affected by the system of learning (e-Learning), laboratory systems (e-Laboratory), the system library (e-Library), and also the curriculum system (e-Curriculum). In addition to the relationship among applications in the cloud, there is a reciprocal relationship between cloud providers and universities. This interrelationship is implemented in the process of interaction of the system use and data updating in the cloud. The relationship between cloud providers and colleges can use the internet.

\section{Architecture Technology}

The successful development of IT architecture-based cloud computing is heavily influenced by the technology used. Figure 3 shows a technology architecture based on a cloud computing architecture model for Muhammadiyah higher education compiled based on the model of development. 

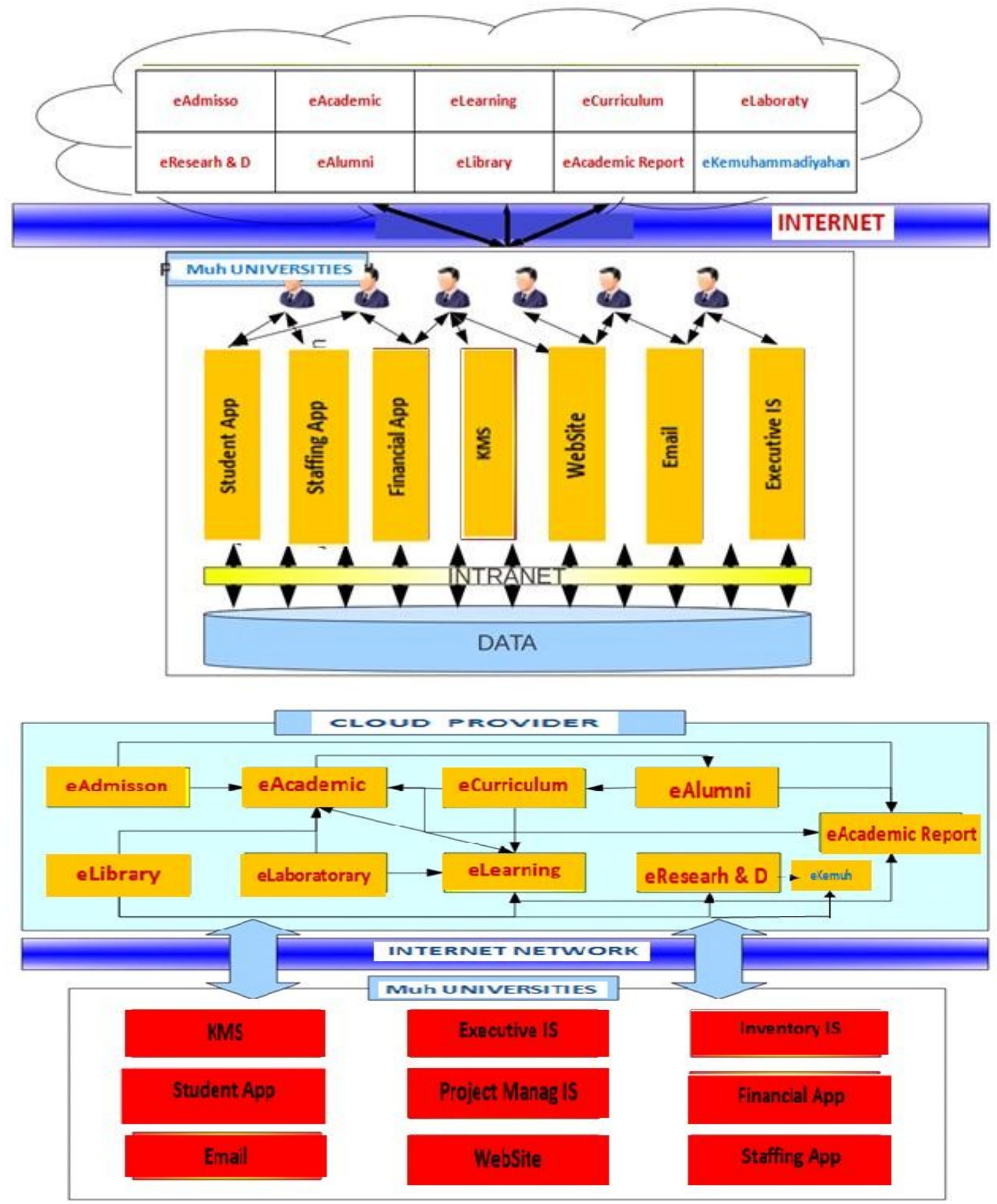

Figure 2. Cloud-based application architecture.

In IaaS, there are several technological components: hardware, software, network services, and infrastructure management. The hardware component involves physical components, such as servers; storage; uninterrupted power supply (UPS); and other supporting components, such as a power source. The software components are especially involved in the operating system and supporting applications, and the virtual 
application server that allows the delivery specifications of different servers for each user according to their respective needs. The components network service organizes data communications services throughout a network. The colleges can use the transmission control protocol (TCP)/Internet protocol (IP) that has been widely used. The latter component is the infrastructure management in charge of organizing the use of the infrastructure, including the use of information infrastructure.

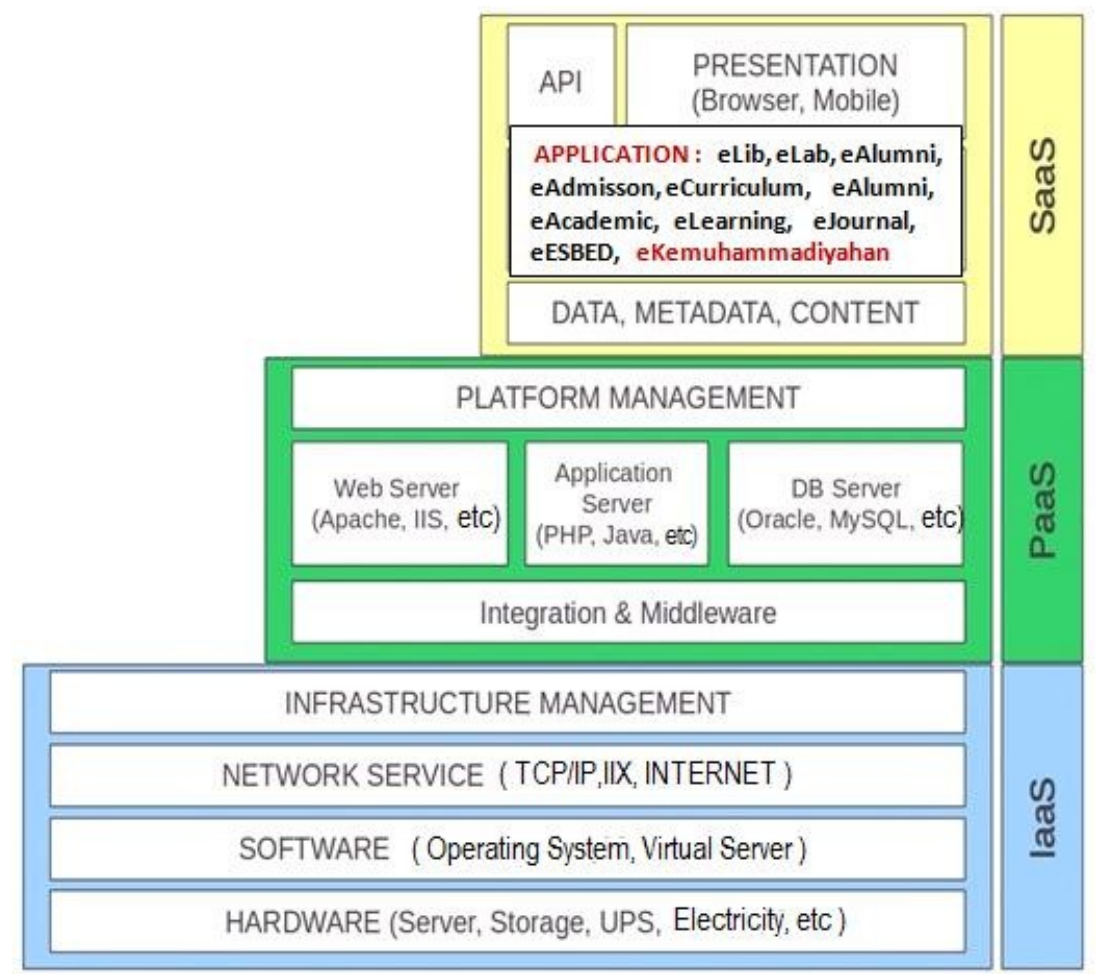

Figure 3. Architecture technology and development of cloud computing.

The second part of the architecture is PaaS. This section consists of several components: Integration \& Middleware serves as the communication link among components, for example, between hypertext processor PHP or Java as a programming language associated with open database connectivity (ODBC) to connect with different types of databases. Other components relate with the necessary platform for the app to run properly. Given the condition of higher education in Indonesia, it is proposed to use a Web-based platform that can be accessed easily. Building Web-based applications requires three basic components, namely, a Web server, such as Apache and Internet Information Services (IIS); server-based application servers, such as PHP; Java; and databases, such as MySQL and Oracle.

The SaaS is the pinnacle of the development model of cloud computing applications. In this section, there are the structural components of the data and metadata required by the application. For HEIs, as already described in the analysis of the application, there are nine applications involved in the services included under SaaS. Each application is associated with the presentation component that regulates the application display in a variety of media, such as browsers and mobile phones. In addition, the application program interface (API) is required to connect the application with other applications that may be developed by the universities.

In addition to model-based development, the technology architecture can also be seen from the cloud provider. The cloud provider, as the party that provides cloud-based services, is the most important in the IT 
architecture proposed for the colleges. The model-generated IT architecture, especially for cloud providers, was created by using the market-oriented model of cloud architecture proposed by Buyya, Yeo, and Venugopal, (2008). The model is divided into four main layers: a layer machine or a physical device, a layer of virtual machines (VMs), an service-level agreement (SLA) resource allocator layer, and the final layer of the user or users.

Layer 1 is a physical infrastructure, which is the most basic part of the IT architecture. Physical infrastructure in the form of application servers is needed, both servers for data processing, the database or web -server, and other server types required by each application. As explained in the previous section, there are nine proposed applications to be put in the cloud. The quality of the server in a cloud-based architecture greatly affects the quality of the services provided. To improve the quality of the server, grid technology can be used in which each computation process can be run (executed) by multiple servers at once. With the division of the process, the speed of the process will be better than without grid technology.

Layer 2 is VMs (the virtual server). The concept of VMs or virtualization will increase the availability of IT services and will reduce the amount of physical infrastructure needed. The virtualization technology also allows any client or users virtually to have full control of the server itself, while physically having to share resources with other clients.

Layer 3 is the SLA resource allocator, the part of the cloud architecture responsible for managing the availability of services for each user. This is the part that connects the applications, ISs, or services provided by the cloud providers with cloud consumers, in this case, the universities. This section is also responsible for receiving service requests from the college, analyzing the feasibility of the requests and responding to them.

Layer 4 is the service users, which is here all the Muhammadiyah Universities. Users can propose a service that is required by the university or, on the contrary, propose the discontinuation of a service if it is no longer needed. The adjustment of services by the users can be done through a portal or application provided by the cloud provider.

\section{Conclusions}

Muhammadiyah Universities network is the largest network of private universities in Indonesia. Therefore, it urgently requires a service-oriented architecture of IT by using virtualization and grid computing technologies. The Muhammadiyah Universities in Indonesia have 10 major ISs that should be placed in the cloud, thus saving the cost of development and implementation. The 10 IS are: (1) the IS for new admissions; (2) the academic IS; (3) the e-learning system; (4) the e-library system; (5) the e-laboratory system; (6) the e-curriculum system; (7) the ISs research and community service; (8) the alumni and career IS; (9) the academic reporting IS; and (10) the Islamic and Kemuhammadiyahan IS (implementation of religion in social life).

By using a cloud-based architecture modeling framework based on users' needs, a model for the IT architecture at Muhammadiyah Universities in Indonesia is produced, which consists of business architecture, data architecture, application architecture, and technology architecture. With the use of the concept of cloud computing, an IT architecture is developed that will solve the problems of redundancy of ISs, data consolidation, data standardization, and inconsistency in the development of ISs. By applying this architectural model, Muhammadiyah Universities will enjoy many benefits since it will save management costs for application development. 
In addition, the presence of third parties to build applications can help Muhammadiyah Universities to focus on their core business processes, namely, education and teaching, research and community service. IT architecture-based cloud computing requires a number of process steps in its implementation. Further consideration is needed, especially on the readiness of internal cloud migration to the external system, because this needs more in-depth consideration of data security aspects of the implementation in education institutions.

\section{References}

Buyya, R., Yeo, C. S., \& Venugopal, S. (2008, September). Market-oriented cloud computing: Vision, hype, and reality for delivering IT services as computing utilities. In The High Performance Computing and Communications (HPCC), 10th IEEE International Conference (pp. 5-13). Tokyo, Japan.

Guin, R. B., Chakrabarti, S., Tarafdar, C., Mandal, S., Banerjee, S., \& Biswas, U. (2011, December). A smart architectural concept for making of a university education system using cloud computing paradigm. In The Information and Communication Technologies (WICT), 2011 World Congress (pp. 48-52). Mumbai, India.

Hewitt, C. (2008). ORGs for scalable, robust, privacy-friendly client cloud computing. IEEE Internet Computing, 12 (5), 96.

Luo, F., Dong, Z. Y., Chen, Y., Xu, Y., Meng, K., \& Wong, K. P. (2012, July). Hybrid cloud computing platform: The next generation IT backbone for smart grid. In The 2012 IEEE Power and Energy Society General Meeting (pp. 1-7). San Diego, California.

Malik, S., Huet, F., \& Caromel, D. (2012, October). Cooperative cloud computing in research and academic environment using Virtual Cloud. In The Emerging Technologies (ICET), 2012 International Conference (pp. 1-7). Slamabad, Pakistan

Minoli, D. (2008). Enterprise architecture A to Z: frameworks, business process modeling, SOA, and infrastructure technology. CRC Press Online.

Open Group. (2009). TOGAF Version 9.1 Enterprise Edition. Retrieved May 15, 2016, from http://www.opengroup.org/archit ecture/togaf8-doc/arch

PP Muhammadiyah. (2015). Laporan Majelis DIKTI PP Muhammadiyah dalam Muktamar 2015. Muktamar Muhammadiyah 2015. Retrieved April 20, 2016, from http://www.muhammadiyah.or.id/id/download-muktamar-muhammadiyah-ke47.html

Seigerroth, U. (2011). Enterprise modeling and enterprise architecture: The constituents of transformation and alignment of business and IT. International Journal of IT/Business Alignment and Governance (IJITBAG), 2(1), 16-34. doi:10.4018/jitbag.2011010102

Solichin, A., \& Hasibuan, Z. A. (2012). Pemodelan arsitektur teknologi informasi berbasis cloud computing untuk institusi perguruan tinggi di Indonesia. Semantik, 2(1).

Undang-Undang, R. I. (2003). Nomor 20 tahun 2003 tentang sistem pendidikan nasional. Jakarta, B.P. : Cipta Jaya.

Wu, C. S., \& Lee, Y. T. (2012, December). Automatic SaaS test cases generation based on SOA in the cloud service. In The Cloud Computing Technology and Science (Cloud Com), 2012 IEEE 4th International Conference (pp. 349-354). Taipei, Taiwan.

Xu, K., Song, M., Zhang, X., \& Song, J. (2009, August). A cloud computing platform based on p2p. In The IT in Medicine \& Education (ITIME), IEEE International Symposium (Vol. 1, pp. 427-432). Xiamen, China.

$\mathrm{Xu}$, X., Jin, H., Wu, S., \& Wang, Y. (2015). Rethink the storage of virtual machine images in clouds. Future Generation Computer Systems, 50(C), 75-86.

Zachman, J. A. (2008). John Zachman's concise definition of the Zachman framework. USA: Zachman CEO Internasional, Inc.. 